\title{
openheart Gender-related differences in self- reported dental care in adults with congenital heart disease at increased risk of infective endocarditis
}

\author{
Susann Schmidt, Marlies Ramseier-Hadorn, Corina Thomet, Kerstin Wustmann, \\ Markus Schwerzmann
}

To cite: Schmidt S,

Ramseier-Hadorn M, Thomet C, et al. Gender-related differences in self-reported dental care in adults with congenital heart disease at increased risk of infective endocarditis. Open Heart 2017;4:e000575. doi:10.1136/ openhrt-2016-000575

Received 25 November 2016 Revised 13 January 2017 Accepted 31 January 2017

\section{(a) CrossMark}

Center for Congenital Heart Disease, University Hospital Inselspital, University of Bern, Bern, Switzerland

Correspondence to Dr Markus Schwerzmann, Center for Congenital Heart Disease, University Hospital Inselspital, Freiburgstrasse, Bern 3010, Switzerland; markus. schwerzmann@insel.ch

\section{ABSTRACT}

Objective Adults with congenital heart disease (CHD) are at increased risk of infective endocarditis $(\mathrm{IE})$. Women with CHD have a lower IE risk, potentially due to gender-related differences in dental care. We aimed to assess selfreported dental hygiene measures in adults with $\mathrm{CHD}$, and to identify factors associated with good oral hygiene. Methods and results Descriptive study includes 187 adults with CHD at increased risk of IE. The patients' IE knowledge was assessed using an adapted version of the Leuven Knowledge Questionnaire for CHD. Their mean age was $34.9 \pm 14.9$ years, 73 of them (39\%) were women, 91 $(49 \%)$ were at high risk for IE, including $66(35 \%)$ with a prosthetic valve, $14(7 \%)$ with a history of IE and $11(6 \%)$ with cyanotic $\mathrm{CHD}$ or residual shunts/valvular regurgitation in the proximity of prosthetic material. The self-defined IE knowledge score did not differ between men and women $(21.6 \pm 10.0$ vs $23.4 \pm 10.0 ; p=0.225) .126$ patients $(67 \%)$ reported to have a good oral hygiene. Female gender (OR $2.4,95 \% \mathrm{Cl} 1.1$ to 4.4 ), and a higher IE knowledge score (OR $1.2,95 \% \mathrm{Cl} 1.1$ to 1.5 , per 5 points) were the variables independently associated with good oral hygiene.

Conclusions In adults with CHD, patients with a higher IE knowledge score and women are more likely to practise dental care as recommended. Gender differences in oral hygiene practise may explain the observed lower female IE incidence rate. Efforts to improve patients' knowledge on IE are encouraged.

\section{INTRODUCTION}

Many adults with congenital heart disease (CHD) are at increased risk of infective endocarditis (IE). Their IE incidence rate of 1 per 1000 patient-years is $10-30$ times higher than the rate in the general population. ${ }^{12}$ As in other patient groups,IE is also a life-threatening complication in patients with CHD with an in-hospital mortality of $2 \%-10 \% .^{3-5}$ Interestingly, women with CHD have a $50 \%$ lower risk of IE than men, independent of the underlying defect. ${ }^{6}$ Women in general are also less likely to have an IE recurrence. ${ }^{7}$ The reasons for this gender difference in IE risk are unclear. It was speculated that women

\section{KEY MESSAGES}

What is already known about this subject? Many adults with congenital heart disease (CHD) are at increased risk of infective endocarditis (IE). Observational studies indicate that women with the same congenital defect have a $50 \%$ lower risk of IE than men, for unknown reasons. It was suspected that gender-related differences in oral hygiene might be one of the contributing factors.

What does this study add?

We aimed to assess the level of oral hygiene measures in adults with $\mathrm{CHD}$ at increased risk of $\mathrm{IE}$, and to identify patient-related characteristics associated with good oral hygiene. Our study showed that a better understanding of the endocarditis disease and female gender were independently associated with better oral hygiene.

How might this impact on clinical practice? Our study supports the hypothesis that gender-related differences in IE risk are related to oral hygiene measures. It provides further arguments that patient education plays an important role in IE prevention. Dental care issues should particularly be addressed in men, as they are less likely to follow standard recommendations for oral hygiene than women.

may practise a better oral hygiene compared with men.

Poor oral hygiene results in plaque and calculus accumulation around the teeth that can lead to gingivitis. Available evidence supports a relationship between oral hygiene and gingival disease parameters, and the risk of developing IE-associated bacteraemia after daily events such as toothbrushing. ${ }^{9}$ Current IE guidelines emphasise the importance of good oral hygiene in the prevention of IE and consider maintenance of optimal oral health even more important than prophylactic antibiotics for dental procedures. ${ }^{1011}$ 
Predictors of good oral health in adult patients with CHD are largely unknown. The aim of this study was to assess self-reported dental hygiene measures in adults with CHD at increased risk of IE, and to identify patient-related characteristics associated with good oral hygiene. Our main study hypothesis was that women have a better self-reported oral hygiene than men.

\section{METHODS}

\section{Study population}

Between November 2012 and February 2014, patients with a regular follow-up at the Center for Congenital Heart Disease of the University Hospital Inselspital were invited to complete a questionnaire about IE knowledge and their oral hygiene practises, if they fulfilled the following criteria: (1) born at an even year, (2) age $>16$ years, (3) at increased risk for IE. Patients with knownlearning disability were excluded. An increased risk of IE was defined as having a cardiac condition with moderate or high IE risk according to the 1997 published American guidelines for the prevention of IE. ${ }^{12}$ We included a broad variety of congenital heart defects from patients at moderate risk (eg. with a small ventricular septal defect or a stenotic bicuspid aortic valve) to patients at high risk (eg. after valve replacement or with cyanotic heart disease not amenable for repair). Data regarding patient characteristics and medical history were retrieved from the hospital records. The study had been submitted to the local ethical committee, who decided that no ethical approval and no informed consent were necessary for this questionnaire.

\section{IE questionnaire/oral hygiene}

Patients' IE knowledge was assessed using parts of the Leuven Knowledge Questionnaire for CHD, developed by Moons et al. ${ }^{13}$ This questionnaire was designed to assess in adults with CHD the patients' general knowledge about their heart defect, their treatment and the prevention of complications. Its IE part was adapted by adding additional IE-specific questions (table 1). The responses to IE questions were scored by two of the authors (MR-H and MS) by consensus as correct, partially correct or incorrect. The highest possible score was 40 points. In addition, patients were asked how often they brush their teeth and how often they have a dental check-up. A good oral hygiene was defined as toothbrushing twice or more a day and having at least oneyearly dental check-up. This is in line with the current recommendations of the American Dental Association for routine dental care in adults. ${ }^{14}$

\section{Statistical analysis}

Data are presented as frequencies for categorical variables or as mean and SD for normally distributed continuous variables, and as median and IQR for non-normally distributed data. Between-group comparisons of continuous variables were performed using a Student's t-test or a Mann-Whitney U test for normally and non-normally distributed data, respectively. The chi-square test was used
Table 1 Infective endocarditis questionnaire

\begin{tabular}{|c|c|}
\hline & Points \\
\hline 1. What is endocarditis? & 8 \\
\hline 2. Indicate the most typical sign of endocarditis? & 8 \\
\hline 3. Does your heart defect increase the risk of endocarditis?* & 4 \\
\hline \multicolumn{2}{|l|}{$\begin{array}{l}\text { 4. Do the following factors contribute to the onset of } \\
\text { endocarditis? }\end{array}$} \\
\hline Smoking or drinking alcohol (correct answer no) ${ }^{\star}$ & 1 \\
\hline Skin infections (correct answer yes) ${ }^{\star}$ & 1 \\
\hline Dental abscess (correct answer yes) & 1 \\
\hline Piercings in oral cavity (correct answer yes) & 1 \\
\hline Tattoo (correct answer yes) & 1 \\
\hline Sexual activity (correct answer no) & 1 \\
\hline Poor nail and skin care (correct answer yes) & 1 \\
\hline Poor dental hygiene (correct answer yes)* & 1 \\
\hline $\begin{array}{l}\text { 5. Can endocarditis damage your heart valves? (correct } \\
\text { answer yes)* }\end{array}$ & 4 \\
\hline 6. When should you take antibiotics?* & 8 \\
\hline
\end{tabular}

Maximal knowledge score was 40 . Questions marked with * were not included in the original Leuven Knowledge Questionnaire for Congenital Heart Disease. ${ }^{13}$

to evaluate differences between categorical data. The associations between good oral hygiene (yes or no) and patients characteristics (ie, age, educational background, gender, etc) were analysed with a univariate logistic regression model. Predictors of good oral hygiene with a $\mathrm{p}$ value $<0.1$ in the univariate analysis were included in a multivariate regression model. In all analyses, the null hypothesis was rejected for $\mathrm{p}$ values $<0.05$. All calculations were performed using STATA 12 statistical software.

\section{RESULTS}

\section{Baseline characteristics of the cohort}

A total of 198 individuals agreed to complete the questionnaire. Of 198 returned questionnaires, 11 were not analysed because the patient fulfilled not all the inclusion criteria $(n=6$; not longer at increased risk for IE, eg, after spontaneous ventricular septal defect closure) or because the participant left more than half of the questions unanswered $(n=5)$. In the end, 187 participants were included in the analysis. Their gender-specific baseline characteristics are presented in table 2. The age range of participants was 16-80 years. Fourteenper cent of patients were younger than 20 years, $33 \%$ in the age range of 20-29 years, $21 \%$ in the age range of 30-39 years and $32 \%$ in the age range of $40-80$ years. According to previous guidelines, ${ }^{12} 91$ patients $(49 \%)$ were at high risk for IE, including 66 patients with an artificial heart valve and 14 patients $(7 \%)$ with a history of IE. Eleven $(6 \%)$ patients had cyanotic heart disease or residual shunts/ valvular regurgitation in the proximity of prosthetic material. No difference was seen between women and men with regard to baseline characteristics, and also the IE 


\begin{tabular}{|c|c|c|c|}
\hline & $\begin{array}{l}\text { Females } \\
(n=73)\end{array}$ & $\begin{array}{l}\text { Males } \\
(n=114)\end{array}$ & $\begin{array}{l}\mathbf{p} \\
\text { Value }\end{array}$ \\
\hline Age, years & $35.1 \pm 14.9$ & $34.8 \pm 15.1$ & 0.916 \\
\hline Social background & & & 0.953 \\
\hline Basic school (n, \%) & $14(19)$ & $22(19)$ & \\
\hline Apprenticeship (n, \%) & $36(49)$ & $64(56)$ & \\
\hline $\begin{array}{l}\text { College/university degree ( } \mathrm{n} \text {, } \\
\%)\end{array}$ & $12(16)$ & $20(18)$ & \\
\hline Missing (n, \%) & $11(15)$ & $8(7)$ & \\
\hline Living situation & & & 0.776 \\
\hline Living with parents (n, \%) & $16(22)$ & $27(24)$ & \\
\hline $\begin{array}{l}\text { Living independently/with } \\
\text { partner }(\mathrm{n}, \%)\end{array}$ & $56(77)$ & $85(75)$ & \\
\hline Missing (n, \%) & $1(1)$ & $2(2)$ & \\
\hline Complexity of cardiac defect & & & 0.252 \\
\hline Mild (n, \%) & $28(38)$ & $39(34)$ & \\
\hline Moderate (n, \%) & $9(12)$ & $25(22)$ & \\
\hline Severe $(n, \%)$ & $36(49)$ & $50(44)$ & \\
\hline Functional class & & & 0.058 \\
\hline NYHA I (n, \%) & $44(60)$ & $87(76)$ & \\
\hline NYHA II (n, \%) & $23(32)$ & $20(18)$ & \\
\hline NYHA III $(\mathrm{n}, \%)$ & $6(8)$ & $7(6)$ & \\
\hline Cyanotic heart disease (n, \%) & $6(8)$ & $5(4)$ & 0.277 \\
\hline Previous endocarditis (n, \%) & $7(10)$ & $6(6)$ & 0.382 \\
\hline Previous valve replacement $(\mathrm{n}, \%)$ & $26(36)$ & $40(35)$ & 0.941 \\
\hline Infective endocarditis risk & & & 0.658 \\
\hline Moderate (n, \%) & $36(49)$ & $60(53)$ & \\
\hline High (n, \%) & 37 (51) & $54(47)$ & \\
\hline $\begin{array}{l}\text { Number of cardiac interventions } \\
\text { in the past }\end{array}$ & & & 0.680 \\
\hline None $(\mathrm{n}, \%)$ & $16(22)$ & 20 (18) & \\
\hline $1(\mathrm{n}, \%)$ & $20(27)$ & 27 (24) & \\
\hline $2(\mathrm{n}, \%)$ & $17(23)$ & $27(24)$ & \\
\hline $3-4(n, \%)$ & $20(27)$ & $40(35)$ & \\
\hline
\end{tabular}

NYHA, New York Heart Association.

knowledge score did not differ between male and female patients $(21.6 \pm 10.0$ vs $23.4 \pm 10.0 ; p=0.225)$. The IE knowledge score per age and gender is depicted in figure 1 .

\section{Oral hygiene and dental check-up}

Thirty-five patients (19\%) indicated that they brush their teeth only once a day or less, and 152 patients $(81 \%)$ indicated that they brushed their teeth at least twice a day. Thirty-five patients (19\%) responded to have a dental check-up less than every year. Four patients did not respond to these questions. Among the 35 patients with no regular dental check-up, 10 (29\%) did also brush their teeth less than twice a day compared with $15 \%$ of patients with regular dental check-up $(\mathrm{p}=0.055)$. Overall, 126 patients $(67 \%)$ were classified as having a good oral hygiene. The gender-specific differences in oral hygiene are listed in table 3. The mean age of patients with good oral hygiene was $33.9 \pm 13.8$ years compared with $37.1 \pm 17.3$ years in the group without good oral hygiene $(\mathrm{p}=0.19)$. Nine of 14 patients $(64 \%)$ with a history of previous IE reported to have a good oral hygiene, this proportion was similar in patients without previous IE episode $(117 / 169,69 \% ; p=0.70)$. Among patients with a college or university degree, $78 \%$ reported to have a good oral hygiene compared with $67 \%$ of patients without this level of education $(\mathrm{p}=0.20)$. Of the 71 women responding to these questions, $79 \%$ had a good oral hygiene compared with $63 \%$ of the men $(\mathrm{p}=0.02)$.

In a univariate logistic regression model, a higher IE knowledge score ((OR) 1.2, 95\% CI 1.1 to $1.5, \mathrm{p}=0.008$, per five points on the score) and female gender (OR 2.4, $95 \%$ CI 1.1 to $4.4, \mathrm{p}=0.021$ ) were each associated with an increased likelihood of a good oral hygiene. Neither the educational level (OR 1.8, 95\% CI 0.7 to 4.4, $\mathrm{p}=0.213$, for college or university degree), nor a history of previous IE (OR $0.8,95 \%$ CI 0.3 to $2.5, \mathrm{p}=0.701$, for a previous IE episode), nor age (OR $-0.07,95 \%$ CI -0.017 to -0.03 , $\mathrm{p}=0.187$, per 5 years of older age), nor the complexity of the defect (OR $0.08,95 \% \mathrm{CI}-0.27$ to -0.43 , $\mathrm{p}=0.64$ ), nor having a prosthetic heart valve (OR $0.30,95 \% \mathrm{CI}$ -0.34 to $-0.95, \mathrm{p}=0.36$ ) were associated with self-reported good oral hygiene.

In a multivariate logistic regression model, female gender (OR 2.1, 95\% CI 1.1 to 4.3, $\mathrm{p}=0.03$ ) and a higher IE knowledge score (OR 1.2, 95\% CI 1.0 to $1.5, \mathrm{p}=0.012$ ) were independent predictors of recommended oral hygiene practises.

\section{DISCUSSION}

In the present study of adults with a congenital heart defect at increased risk of IE, female gender and a higher IE knowledge score were both associated with a higher likelihood of self-reported good oral hygiene, independent of the participants' educational background, their IE risk and their previous medical history.

In the revised American guidelines for the prevention of IE in 2008, the efficacy of antibiotic prophylaxis to prevent IE episodes was doubted, and attention was called tothe importance of good oral health and hygiene as preventive measures. ${ }^{11}$ In the most recent European guidelines from 2015, this concept has been preserved. ${ }^{10}$ However, the guidelines are vague on what constitutes a good oral hygiene. National dental organisations, for example, the American Dental Organization or the German Dental Organization as European example, recommend all adults to brush their teeth twice a day and to schedule regular dental visits in order to maintain good oral health. ${ }^{14}$ In the present study, these general recommendations were used as specific definition of good oral hygiene for the patients.

In the most recent Swiss Health Survey published in 2012 and including $>25000$ private households 


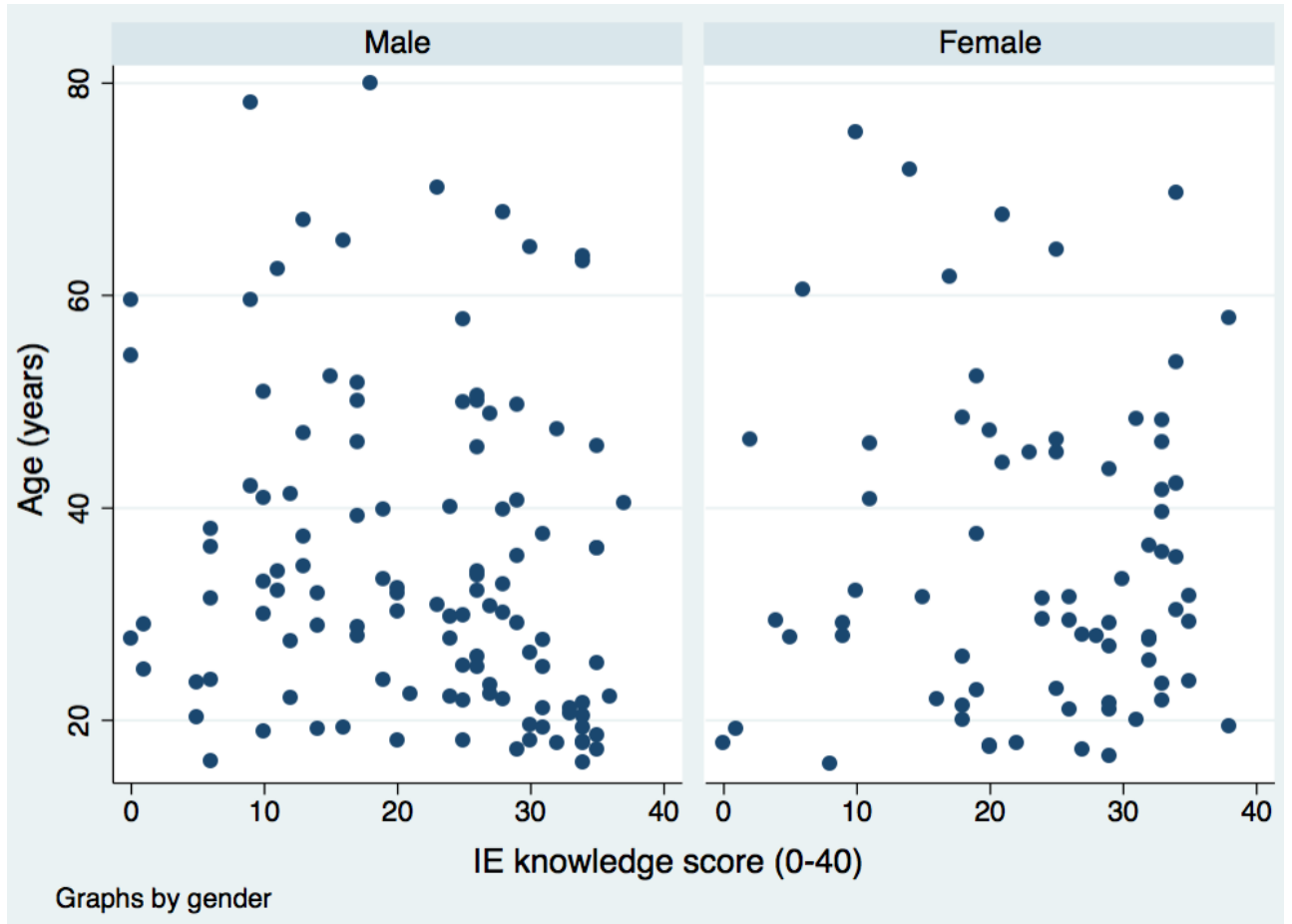

Figure 1 Correlation between the IE knowledge score and age in men and women. IE, infective endocarditis.

throughout the country, $62 \%$ of the population reported to have had a dental visit in the previous year. ${ }^{15}$ In the age group of 15-74 years, regular dental visits were more frequent in women compared with men (68\% vs $63 \%)$, in Swiss compared with non-Swiss citizens (63\% vs 54\%), and in those with higher incomes. Compared with other European countries, Swiss residents are slightly less likely to have a yearly dental visit. ${ }^{1617}$ In Switzerland, dental visits are not covered by the compulsory basic health insurance, probably explaining why adults with lower income may not be able to afford a yearly dental visit. In light of these numbers, the present study showed that adult patients with CHD went more often $(79 \%)$ for dental visits than the average Swiss resident $(\mathrm{p}<0.001)$, and were

\begin{tabular}{|c|c|c|c|}
\hline & $\begin{array}{l}\text { Females } \\
(n=73)\end{array}$ & $\begin{array}{l}\text { Males } \\
(n=114)\end{array}$ & $\begin{array}{l}p \\
\text { Value }\end{array}$ \\
\hline Total IE knowledge score & $23.4 \pm 9.9$ & $21.6 \pm 10.0$ & 0.225 \\
\hline \multicolumn{4}{|l|}{ Oral hygiene } \\
\hline Toothbrushing & & & 0.030 \\
\hline Less than twice a day $(\mathrm{n}, \%)$ & $8(11)$ & $27(24)$ & \\
\hline Twice a day or more $(\mathrm{n}, \%)$ & $65(89)$ & $87(76)$ & \\
\hline Dental visit & & & 0.320 \\
\hline Less than every year $(n, \%)$ & $11(15)$ & $24(21)$ & \\
\hline Yearly or more (n, \%) & $60(82)$ & $88(77)$ & \\
\hline Missing (n, \%) & 2 (2) & 2 (2) & \\
\hline Good oral hygiene (n, \%) & $56(79)$ & $70(62)$ & 0.022 \\
\hline
\end{tabular}

$\mathrm{IE}$, infective endocarditis. also more likely to clean their teeth at least twice a day ( $74 \%$ in the Swiss Health Study vs $81 \%$ in our patients, $\mathrm{p}=0.022$ ). As it had been reported for dental visits, Swiss women in general were more conscientious about daily dental care: $82 \%$ of women reported to brush their teeth twice or more a day compared with $66 \%$ of men. This attitude is also reflected in the present study, although on a higher level of care. Therefore, the findings of this study are in favour of the hypothesis that better oral hygiene may contribute to the lower IE risk in women with CHD compared with men.

The observation that men are at higher risk of IE than women is supported by different publications. In 2004, Moreillon and Que quoted in a review analysing 26 publications with $>3700$ episodes of IE a male to female ratio of 2:1. ${ }^{18}$ In another epidemiological study from Olmsted County published in 2005, the age-adjusted incidence rate of IE over a 30 years period differed substantially in women versus men $(2-4 / 100000$ patient-years in women and $8-12 / 100000$ patient-years in men). ${ }^{19}$ In the most recent data analysis of the CONCOR registry (CONgenital CORvitia Dutch national registry database) including $>10000$ patients with a CHD, the HR for women to develop IE was 0.5 (95\% CI 0.4 to 0.6$)$ compared with men, adjusted for other known predictors of IE risk inpatients with CHD. ${ }^{1}$ In the present study, the number of patients with a history of previous IE was similar in women and men. Given the low number of events in our small study population, the current survey was not powered to assess any gender-related IE risk difference.

The reasons for a gender difference in IE risk are unknown. A less risky behaviour in women versus men was thought to contribute. Men are, for example, more likely 
to consume intravenous drugs than women, putting them at higher risk for right-sided and left-sided IE. ${ }^{20}$ On the other hand, other more common but less risky procedures like body piercing seem to be more common in women or in the case of tattooing, equally common in both sexes. ${ }^{21}$ Vasoprotective effects of oestrogen were also discussed as explanation, rendering the endothelial lining of heart valves in women less susceptible to damage and therefore, less predisposed to infection with IE causing organisms. ${ }^{22}$ As far as we know, a gender-specific difference in IE risk cannot be attributed to differences in oral bacterial flora. ${ }^{23}$ In a recent study investigating systemically all patients with IE for the most likely port of entry of the disease-causing organism, an oral or dental port of entry was assumed in $29 \%$ of all identified episodes. ${ }^{24}$ A dental infectious focus was more often involved than a dental procedure. All in all, it is reasonable to assume that dental hygiene plays a pivotal role in the prevention of IE, and gender-related difference in oral hygiene are a plausible reason for the higher IE risk in men compared with women.

Another important finding of this study was the independent association of IE knowledge with good oral hygiene. This finding supports current concepts reinforcing the importance of patient education as a way to improve their cardiac-related outcome. ${ }^{25}$ In our institution, we routinely question patients with CHD about their IE knowledge and highlight the importance of a good oral hygiene.

The following limitations have to be acknowledged: the present study investigated a relatively small sample of patients, followed at a single tertiary centre. The results obtained at this centre may not be representative for other centres and countries. Furthermore, it is possible that patients responding to the questionnaire reported a better oral hygiene than they actually had. This bias and a selection bias of patients willing to participate in the survey were more likely to confound the results of this present study than they might confound the results of the anonymous and large scale Swiss Health Study, offering an explanation for the observed differences in dental care between the present patients and the general population. It is however less likely, that these biases may also account for the observed gender difference in this study. In addition, assessing simply the frequency of toothbrushing does not provide the full picture regarding the overall quality of oral hygiene.

Based on this study results, it is recommended to reinforce the importance of good oral care in daily clinical routine. Oral care issues should particularly be addressed in men, as they are less likely to follow standard recommendations for oral hygiene than women. From a practical standpoint, the frequency and the duration and quality of oral care should be discussed.

Acknowledgements The authors thank Margrit Huber and Odette Egli from the Center for Cogenital Heart Disease for their logistic support.

Contributors MR-H, CT and MS conceived and designed the study; MR-H, CT, KW and MS collected the data; SS, MR-H and MS undertook the statistical analysis; SS and MS drafted the manuscript; all authors had full access to all the data, including statistical reports and tables; all authors analysed and interpreted the data; all authors critically revised the manuscript for important intellectual content; MS is the guarantor.

Competing interests None declared.

Provenance and peer review Not commissioned; internally peer reviewed.

Data sharing statement No additional data are available.

Open Access This is an Open Access article distributed in accordance with the Creative Commons Attribution Non Commercial (CC BY-NC 4.0) license, which permits others to distribute, remix, adapt, build upon this work non-commercially, and license their derivative works on different terms, provided the original work is properly cited and the use is non-commercial. See: http://creativecommons.org/ licenses/by-nc/4.0/

(c) Article author(s) (or their employer(s) unless otherwise stated in the text of the article) 2017. All rights reserved. No commercial use is permitted unless otherwise expressly granted.

\section{REFERENCES}

1. Verheugt CL, Uiterwaal CS, van der Velde ET, et al. Turning 18 with congenital heart disease: prediction of infective endocarditis based on a large population. Eur Heart J 2011;32:1926-34.

2. Cahill TJ, Prendergast BD. Infective endocarditis. The Lancet 2016;387:882-93.

3. Knirsch W, Nadal D. Infective endocarditis in congenital heart disease. Eur J Pediatr 2011;170:1111-27.

4. Di Filippo S, Delahaye F, Semiond B, et al. Current patterns of infective endocarditis in congenital heart disease. Heart 2006;92:1490-5.

5. Knirsch W, Haas NA, Uhlemann F, et al. Clinical course and complications of infective endocarditis in patients growing up with congenital heart disease. Int J Cardiol 2005;101:285-91.

6. Verheugt CL, Uiterwaal CS, van der Velde ET, et al. Gender and outcome in adult congenital heart disease. Circulation 2008;118:26-32.

7. Shih CJ, Chu H, Chao PW, et al. Long-term clinical outcome of major adverse cardiac events in survivors of infective endocarditis: a nationwide population-based study. Circulation 2014;130:1684-91.

8. Warnes CA. Sex differences in congenital heart disease: should a woman be more like a man? Circulation 2008;118:3-5.

9. Lockhart PB, Brennan MT, Thornhill M, et al. Poor oral hygiene as a risk factor for infective endocarditis-related bacteremia. J Am Dent Assoc 2009;140:1238-44.

10. Habib G, Lancellotti P, Antunes MJ, et al; Document Reviewers. 2015 ESC guidelines for the management of infective endocarditis: the task force for the management of infective endocarditis of the European Society of Cardiology (ESC). Endorsed by: European Association for Cardio-Thoracic Surgery (EACTS), the European Association of Nuclear Medicine (EANM). Eur Heart $J$ 2015;36:3075-128

11. Wilson W, Taubert KA, Gewitz M, et al. Prevention of infective endocarditis: guidelines from the American Heart Association: a guideline from the American Heart Association Rheumatic Fever, Endocarditis, and Kawasaki Disease Committee, Council on Cardiovascular Disease in the Young, and the Council on Clinical Cardiology, Council on Cardiovascular Surgery and Anesthesia, and the Quality of Care and Outcomes Research Interdisciplinary Working Group. Circulation 2007;116:1736-54.

12. Dajani AS, Taubert KA, Wilson W, et al. Prevention of bacterial endocarditis. recommendations by the American Heart Association. JAMA 1997;277:1794-801.

13. Moons P, De Volder E, Budts W, et al. What do adult patients with congenital heart disease know about their disease, treatment, and prevention of complications? A call for structured patient education. Heart 2001;86:74-80.

14. American Dental Association. Dental disease is preventable 2016. http://www.mouthhealthy.org/en/adults-under-40/ (accessed 07.08.2016).

15. Stadelmann $P$, Zemp E, Weiss $C$, et al. Dental visits, oral hygiene behaviour, and orthodontic treatment in Switzerland. Schweiz Monatsschr Zahnmed 2012;122:104-26.

16. Visser RS, Heling GW, Burgersdijk RC, et al. [National dental health survey. 4. dental visits. 1. behavior and knowledge]. Ned Tijdschr Tandheelkd 1991;98:499-501.

17. Micheelis W, Schiffner U. Vierte Deutsche Mundgesundheitsstudie (DMS IV). Deutscher Zahnärzte Verlag DÄV 2006:380-5. 
18. Moreillon P, Que Y-A. Infective endocarditis. The Lancet 2004;363:139-49.

19. Tleyjeh IM, Steckelberg JM, Murad HS, et al. Temporal trends in infective endocarditis: a population-based study in Olmsted County, Minnesota. JAMA 2005;293:3022-8.

20. Mathew J, Addai T, Anand A, et al. Clinical features, site of involvement, bacteriologic findings, and outcome of infective endocarditis in intravenous drug users. Arch Intern Med 1995;155:1641.

21. Laumann AE, Derick AJ. Tattoos and body piercings in the United States: a national data set. J Am Acad Dermatol 2006;55:413-21.
22. Bakir S, Mori T, Durand J, et al. Estrogen-induced vasoprotection is estrogen receptor dependent: evidence from the balloon-injured rat carotid artery model. Circulation 2000;101:2342-4.

23. Bik EM, Long CD, Armitage GC, et al. Bacterial diversity in the oral cavity of 10 healthy individuals. ISME J 2010;4:962-74.

24. Delahaye F, M'Hammedi A, Guerpillon B, et al. Systematic search for present and potential portals of entry for infective endocarditis. J Am Coll Cardiol 2016;67:151-8.

25. Kovacs $\mathrm{AH}$, McCrindle BW. So hard to say goodbye: transition from paediatric to adult cardiology care. Nat Rev Cardiol 2014;11:51-62. 